\title{
Retropharyngeal Lymph Node Metastasis from Thyroid Papillary Carcinoma with Airway Obstruction
}

\author{
TaeUk Cheon ${ }^{\mathbb{D}}$, Jin Il Kim, TaeKoon Kim, and Myung Woul Han $\mathbb{B}$ \\ Department of Otolaryngology, Ulsan University Hospital, University of Ulsan College of Medicine, Ulsan, Korea \\ 기도폐쇄를 동반한 갑상선 유두암의 후인두 림프절 전이 \\ 천태욱 · 김진일 · 김태군 · 한명월 \\ 울산대학교 의과대학 울산대학교병원 이비인후과학교실
}

\author{
Received March 21, 2019 \\ Revised May 23, 2019 \\ Accepted May 24, 2019 \\ Address for correspondence \\ Myung Woul Han, MD, PhD \\ Department of Otolaryngology, \\ Ulsan University Hospital, \\ University of Ulsan \\ College of Medicine, \\ 877 Bangeojinsunhwando-ro, \\ Dong-gu, Ulsan 44033, Korea \\ Tel $+82-52-250-8922$ \\ Fax $+82-52-250-7182$ \\ E-mail brightmoon@uuh.ulsan.kr
}

Lymph node metastases of thyroid papillary carcinomas typically occur in the central and lateral neck lymph nodes. Metastasis to the retropharyngeal node is rare for this tumor type, especially when accompanied with airway obstruction. We treated one patient with retropharyngeal lymph node (RPLN) metastasis of thyroid papillary carcinoma with airway obstruction. The RPLN was successfully resected without complications via transcervical approach. Although the present case is rare, metastasis to the retropharyngeal nodes should be considered at the time of diagnosis and follow-up for thyroid papillary carcinoma. The dissection of thyroid papillary carcinoma metastases to the RPLN should be based on estimated prognosis, complaints, performance status, surgical skill, and complications.

Korean J Otorhinolaryngol-Head Neck Surg 2020;63(1):40-4

Key Words Neck dissection · Papillary carcinoma · Retropharyngeal lymph node Thyroid cancer.

\section{Introduction}

Thyroid papillary carcinoma shows lymphatic spread in approximately $40-50 \%$ of cases. ${ }^{1)}$ Nodal involvement commonly occurs in the central region and lateral compartments of the neck ${ }^{2}$; however, metastases to the retropharyngeal lymph nodes (RPLNs) are very rare for thyroid carcinoma. ${ }^{3-6)}$ The RPLNs are located within the retropharyngeal space. The pharyngeal constrictor muscles border this space anteriorly, the prevertebral fascia posteriorly, the carotid sheath laterally, and the skull base superiorly, while the space continues to the level of the caudal aspect of the $\mathrm{C} 3$ vertebra inferiorly. There are two groups of lateral and medial RPLNs. These lymph nodes are very small and are rarely present in adults. ${ }^{7)}$

This is an Open Access article distributed under the terms of the Creative Commons Attribution Non-Commercial License (https://creativecommons.org/licenses/by-nc/4.0) which permits unrestricted non-commercial use, distribution, and reproduction in any medium, provided the original work is properly cited.
In general, it has been known that metastatic cervical lymph nodes or prior neck dissection itself might alter the direction of lymphatic drainage to the retrograde pathway, resulting in unusual metastasis to the RPLNs. ${ }^{5)}$ There are two lymphatic pathways linked to RPLNs metastasis from this type of tumor: one pathway is retrograde from jugular chain lymphatics, and the other is the direct posterosuperior lymphatic trunk pathway from the upper pole of the thyroid. ${ }^{8)}$

Herein, we report a very rare case of RPLN metastasis of thyroid papillary carcinoma with airway obstruction.

\section{Case}

A 36-year-old man visited our clinic in September 2014 complaining about a very large mass in his right side neck as well as progressive dyspnea since 20 years. He had already been diagnosed with thyroid papillary carcinoma with right 
lateral neck lymph node and RPLN metastases at our clinic in 2010. However, he had not undergone surgery for personal reasons, and the tumor size increased over time. When he revisited our hospital, the patient complained of the following symptoms associated with a retropharyngeal mass: throat discomfort, dysphagia, nasal obstruction, snoring, sleep apnea, voice change, and dyspnea. Upon physical examination, a very large RPLN in the oral cavity was visible to the naked eye. A deviation of the uvula to the left and a displacement of the tonsil fossa and soft palate due to the RPLN were evident, and the right RPLN occupied most of the nasopharyngeal and oropharyngeal airways (Fig. 1). Therefore, we could not perform a fiber-optic laryngoscopy to examine the larynx. In addition, multiple right neck masses were palpable. We performed fine needle aspiration cytology for the thyroid nodule and the right neck mass, the results of which indicated thyroid papillary carcinoma and metastatic papillary carcinoma. Preoperative contrast-enhanced CT showed two wellenhanced large solid and cystic metastases at the right neck level 2 to 4 lymph nodes and right RPLN swelling with a narrowing pharyngeal airway (Fig. 2). On CT, the RPLN encircled the internal and external carotid artery about $180^{\circ}$. Additionally, we performed angiography and occlusion tests and identified sufficient collateral arterial flow from the contralateral internal carotid artery. And inside the right thyroid lobe, there was $3 \mathrm{~cm}$ sized calcified and predominantly cystic nodule without extracapsular extension (Fig. 3).

At first we performed temporary tracheostomy under local anesthesia because of the huge RPLN mass which precluded endotracheal intubation. After tracheostomy the main
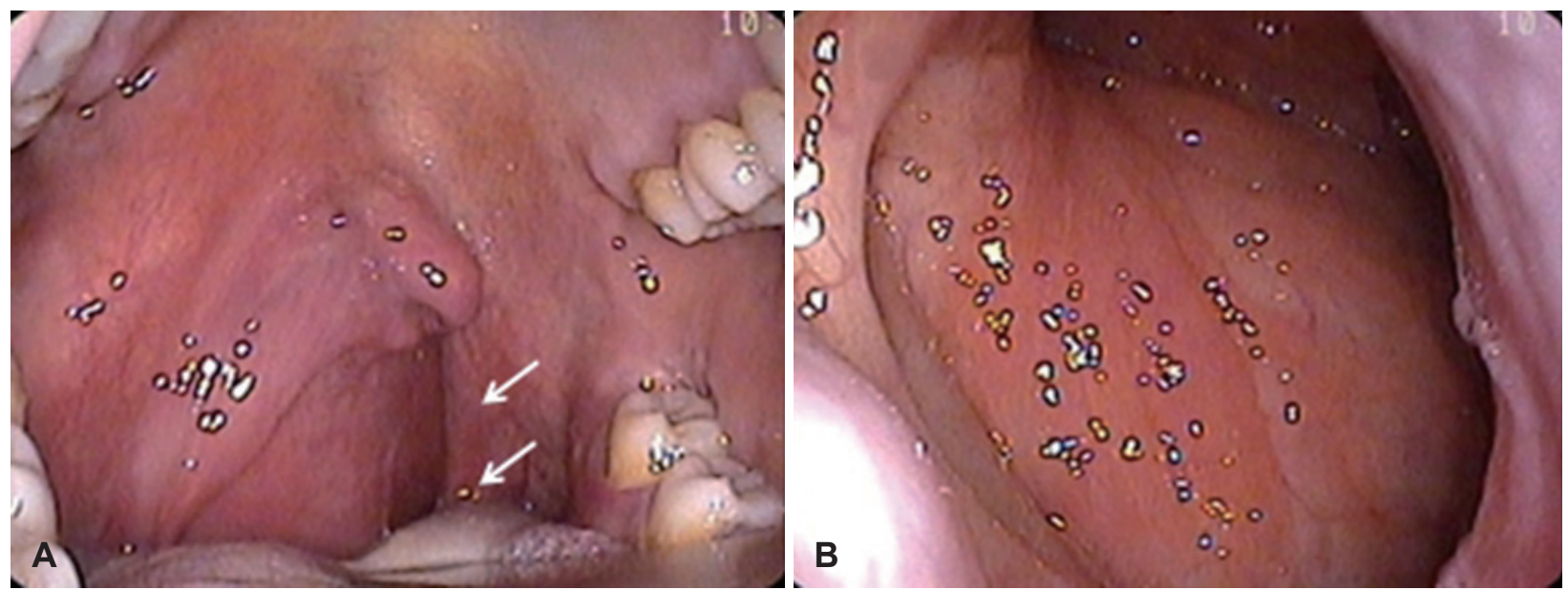

Fig. 1. Physical examination findings. Trans-oral endoscopic view of a deviation of the uvula to the left and a displacement of the tonsil fossa and soft palate due to RPLNs (arrows) are evident (A). Trans-nasal endoscopic view of the right RPLN occupies most of the pharyngeal airway (B). RPLN: retropharyngeal lymph node.
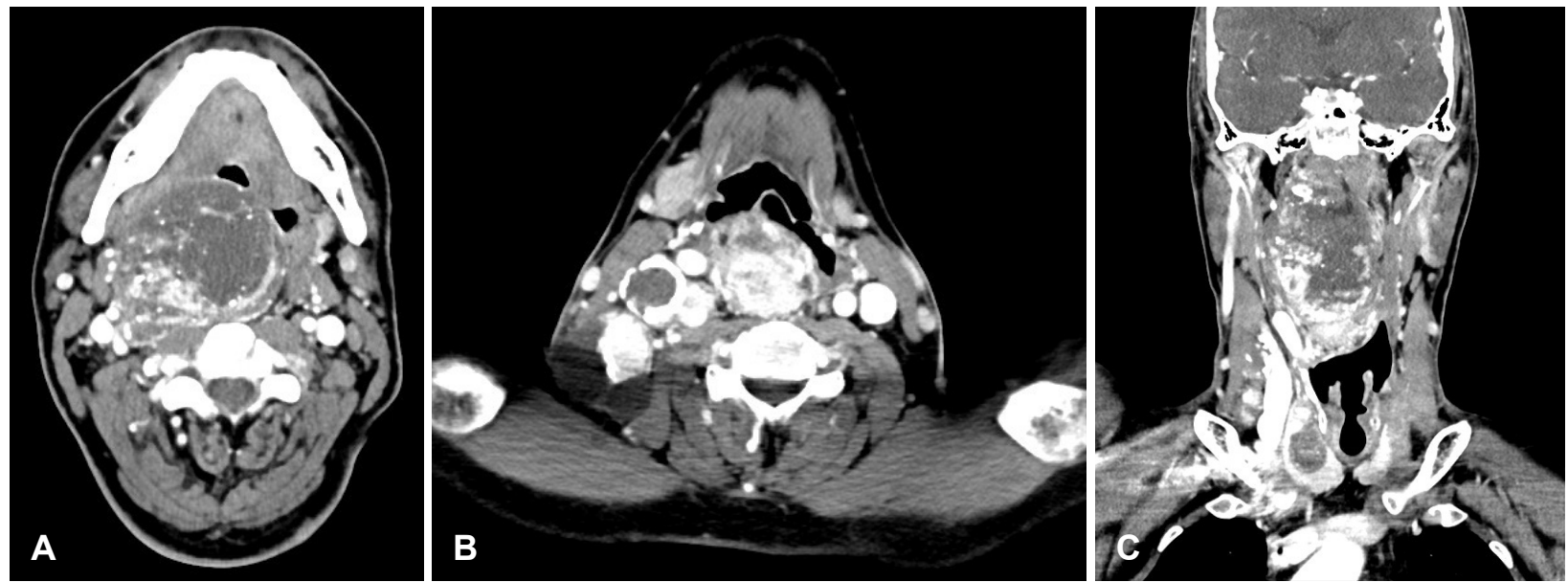

Fig. 2. CT imaging findings. Axial view of CT scan showing the right RPLN resulting in narrowing of the airway is observed in the retropharyngeal space (A). Axial view of two well-enhanced large solid and cystic metastases at right level 2 to 4 lymph nodes (B). Coronal view of the right RPLN (C). CT: computed tomography, RPLN: retropharyngeal lymph node. 
surgery was done including total thyroidectomy, central neck dissection, and right neck dissection (Level II-V). In the surgical field, fortunately, the right RPLN had not invaded the carotid artery. And after resection of digastric muscle and stylohyoid muscle and sternocleidomasoid muscle we could approach and totally remove the RPLN mass without procedure of mandibulotomy. Pathologist confirmed that $3.7 \mathrm{~cm}$ right side papillary carcinoma without perineural invasion of thyroid. And it extended to perithyroidal soft tissue. And there were 15 metastatic lymph nodes out of 46 lymph nodes (Level II A: 3/5, Level II B: 1/5, Level III: 4/12, Level IV: 0/6, Level Va: 0/1, Level Vb: 2/3, Level VI: 5/14). Also the $7.5 \mathrm{~cm}$ sized RPLN mass was confirmed to metastatic papillary carcinoma with extranodal extension (Figs. 4 and 5).

The patient developed slight dysphagia postoperatively, but spontaneously recovered before discharge. It took no more than two weeks. His preoperative symptoms caused by huge RPLN were all disappeared and his airway was intact on fi- beroptic laryngoscopy after operation (Fig. 6). And there wasn't any complication such as bleeding, other nerve dysfunctions, or abscesses. Two months later after the patient discharged (70 days after operation) he underwent postoperative iodine-131 therapy $(200 \mathrm{mCi})$. The endocrinologist considered second iodine-131 therapy at that time, but all of his result of CT, ultrasonography and thyroid function test were normal. So the endocrinologist decided to do regular follow up without additional iodine therapy. There was no evidence of tumor recurrence in the almost 5 years following surgery.

\section{Discussion}

Metastases to the RPLN are found more frequently in cases of lymphoma and pharyngeal or sinonasal squamous cell carcinomas and are very rare in thyroid papillary carcinoma. And they are exceedingly rare in thyroid follicular carcinoma. ${ }^{9}$ Togashi et al. ${ }^{6}$ reported that RPLN metastases were diagnosed
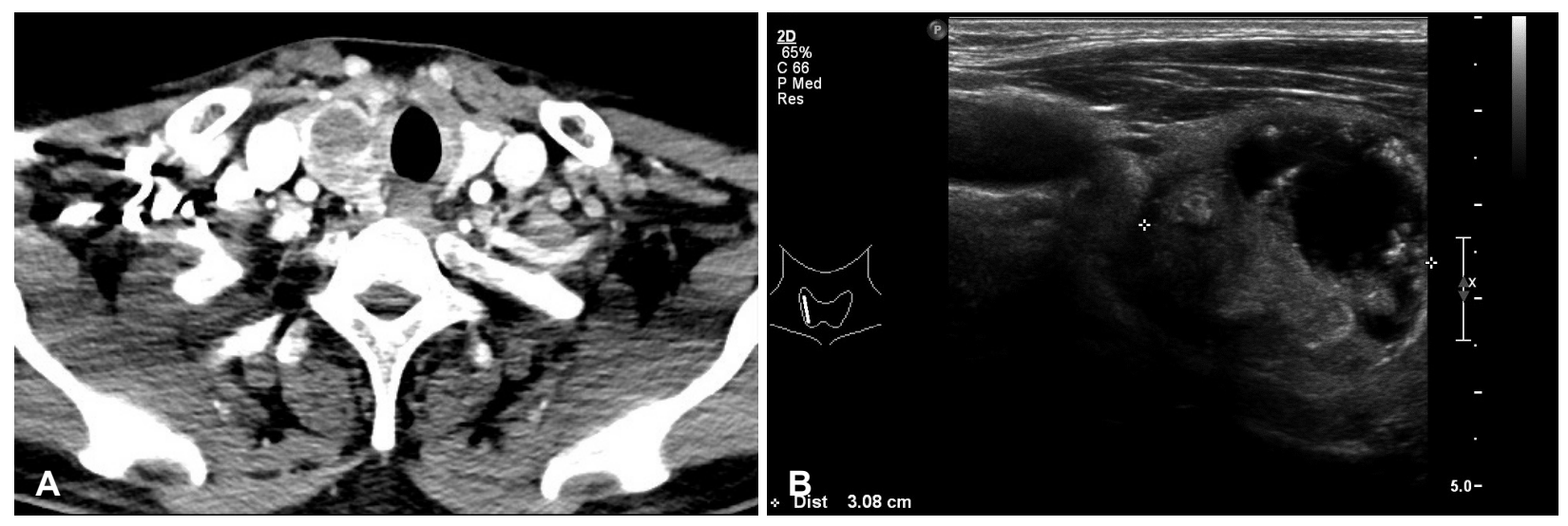

Fig. 3. CT and ultrasonography of thyroid mass. CT scan showing low density right thyroid mass without gross extracapsular extension (A). Ultrasonography of right thyroid mass (an about $3 \mathrm{~cm}$ sized, predominantly cystic, mild hypoechoic to isoechoic, heterogenous and well defined mass with microcalcification) (B).

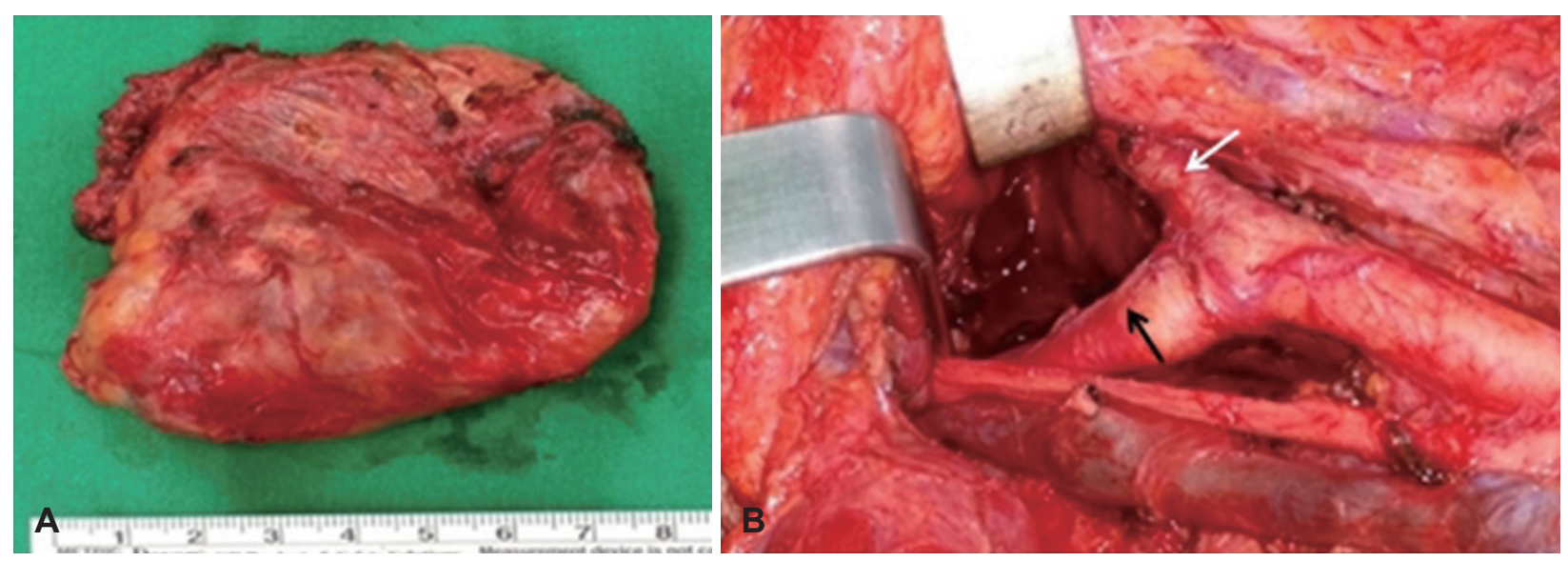

Fig. 4. Gross findings. The size of resected retropharyngeal lymph node was $7.5 \times 6.9 \times 3.2 \mathrm{~cm}(\mathrm{~A})$. The tumor was dissected via a transcervical approach without internal/external carotid artery injury (white arrow: external carotid artery, black arrow: internal carotid artery) (B). 

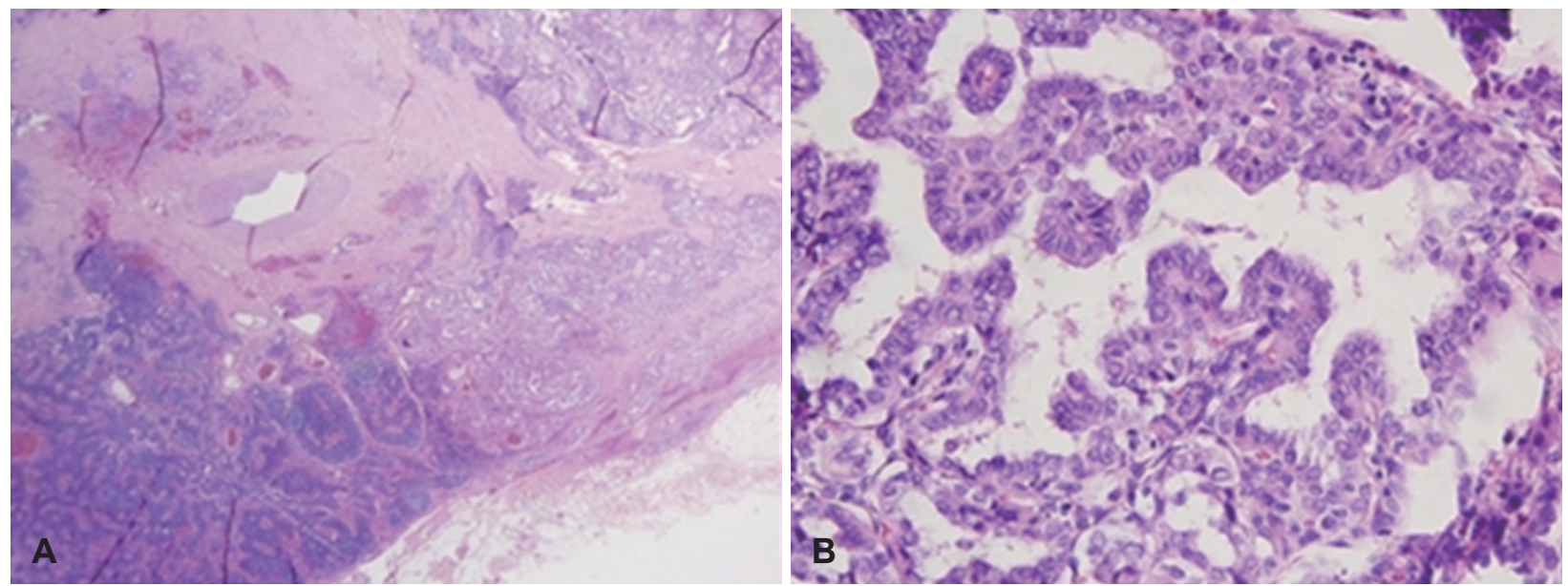

Fig. 5. Histopathological findings. The retropharyngeal lymph node shows papillary growth pattern with typical nuclear features of thyroid papillary carcinoma $(H \& E$ stain, $\times 20)(A)$. Higher magnification of the tumor cells showing large oval nuclei with ground glass, reminiscent of a thyroidpapillary carcinoma (H\&E stain, $\times 400)(B)$. H\&E: hematoxylin and eosin.

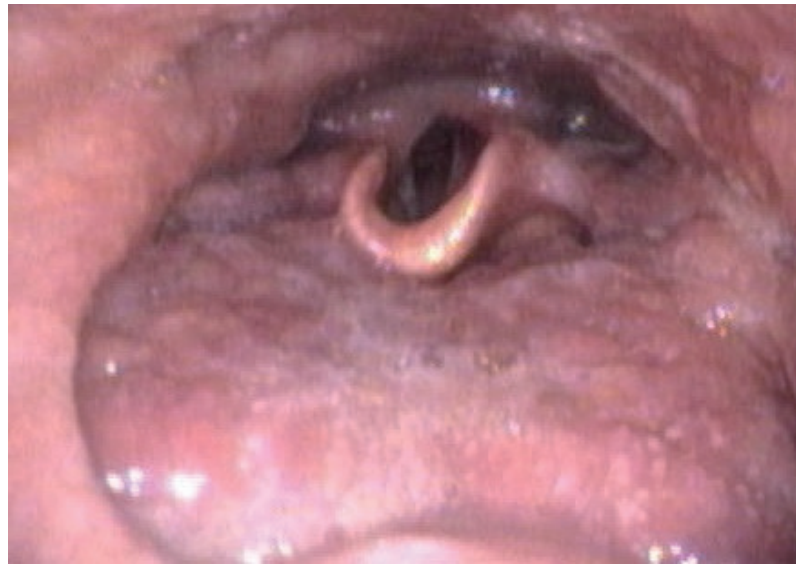

Fig. 6. Postoperative physical examination. Trans-nasal endoscopic view of pharynx where huge right retropharyngeal lymph node was before.

in 12 of $1449(0.08 \%)$ patients who underwent surgery for thyroid papillary carcinoma over a 19 -year period. And all of their symptoms were dysphagia and throat discomfort or nothing. There was no as large mass as our case and there was no patient with dyspnea.

The RPLNs can be located at the medial side of the internal carotid artery and sympathetic chain, and are usually seen at the level of the arch of $\mathrm{Cl}^{3,4)}$ The lymphatics of the thyroid gland can be classified into the following four groups ${ }^{8}$ : 1) the superomedial trunk ending with the prelaryngeal node, 2) the superolateral trunk ending in the cervical nodes of the upper jugular chain, 3) the inferomedial trunk ending in the preand paratracheal nodes, and 4) the inferolateral trunk ending in the supraclavicular and jugulosubclavian nodes. However, Rouviére and Tobias $^{8)}$ reported additional pathways. One of them is retrograde from the jugular chain lymphatics, and the other is the direct posterosuperior lymphatic trunk pathway. The latter pathway is the lymphatic pathway extending from the upper pole of the thyroid gland to the lateral RPLN. This connection was present in $20 \%$ of his anatomic dissections. Likewise, we thought that the posterosuperior collecting trunk pathway was possibly the lymphatic pathway connecting the thyroid gland to the RPLN.

This case suggests that metastatic cervical lymph nodes might alter the direction of lymphatic drainage to the retrograde pathway, resulting in the unusual metastasis to the RPLNs. ${ }^{3)}$ Therefore, if lymph node metastases originating from thyroid carcinoma are identified in the upper jugular chain, although the probability of them occurring is very low, RPLN metastases should be considered at the time of diagnosis and follow-up for thyroid papillary carcinoma. ${ }^{6}$

In this case, the patient had exceptionally large RPLN metastasis. However, generally, RPLN metastases are difficult to examine clinically because of their small size and location in the retropharyngeal space. Therefore, preoperative imaging is necessary to check for RPLN metastasis. Thyroid disease and lymphadenopathy in the lateral neck have been evaluated by using ultrasonography; however, it is not possible to use this tool to evaluate metastases to the RPLN. If lymph node metastases originating from a thyroid carcinoma are identified in the upper jugular chain region, contrast-enhanced CT is recommended.

In the case of RPLN, complete surgical removal is the main therapy, with a transcervical approach being used more often than a transoral approach. The advantage of transoral approach 
considering the retropharyngeal space is its minimally invasive nature. However, the main disadvantage of this approach is that it makes immediate access to the internal carotid artery and jugular vessels difficult. ${ }^{4)}$ The risk of uncontrollable bleeding must therefore be considered. It is difficult to use the transoral approach in cases of very large masses encircling the internal carotid artery such as this one. Therefore, the transcervical approach is the most common approach used in cases of very large metastatic masses at the RPLN. The advantage of the transcervical approach is that if additional exposure of the surgical field is needed, resection of part of the mandibular angle can be performed without using atransmandibular swing approach. ${ }^{5,6)}$ However, if there is close adhesion between the metastatic lymph node and surrounding tissue, especially major vessels, a combined transcervical and mandibular swing approach should be carried out. ${ }^{5)}$ In our case, the RPLN could be resected safely via a transcervical approach without mandibulotomy.

In conclusion, although the present case is rare, metastasis to the retropharyngeal nodes should be considered at the time of diagnosis and follow-up for thyroid papillary carcinoma. Most RPLN metastases from thyroid papillary carcinoma could be dissected safely without mandibulotomy in the present case. The dissection of thyroid papillary carcinoma metastases to the RPLN should be based on estimated prognosis, complaints, performance status, surgical skill, and complications.

\section{Author Contribution}

Conceptualization: Myung Woul Han. Data curation: TaeKoon Kim, Jin Il Kim, TaeUk Cheon. Formal analysis: Myung Woul Han, TaeUk Cheon. Investigation: TaeKoon Kim, Jin Il Kim, TaeUk Cheon.
Methodology: Myung Woul Han. Project administration: Myung Woul Han. Resources: Myung Woul Han. Supervision: Myung Woul Han. Validation: Myung Woul Han. Visualization: Myung Woul Han, TaeUk Cheon. Writing — original draft: TaeUk Cheon. Writing - review \& editing: Myung Woul Han, TaeUk Cheon.

\section{ORCID}

Myung Woul Han https://orcid.org/0000-0001-8596-7699

TaeUk Cheon https://orcid.org/0000-0002-5808-1240

\section{REFERENCES}

1) Shaha AR, Shah JP, Loree TR. Patterns of nodal and distant metastasis based on histologic varieties in differentiated carcinoma of the thyroid. Am J Surg 1996;172(6):692-4.

2) Yüce I, Cağli S, Bayram A, Karasu F, Güney E. Regional metastatic pattern of papillary thyroid carcinoma. Eur Arch Otorhinolaryngol 2010;267(3):437-41.

3) Otsuki N, Nishikawa T, Iwae S, Saito M, Mohri M, Nibu K. Retropharyngeal node metastasis from papillary thyroid carcinoma. Head Neck 2007;29(5):508-11.

4) Shellenberger T, Fornage B, Ginsberg L, Clayman GL. Transoral resection of thyroid cancer metastasis to lateral retropharyngeal nodes. Head Neck 2007;29(3):258-66.

5) Kainuma K, Kitoh R, Yoshimura H, Usami S. The first report of bilateral retropharyngeal lymph node metastasis from papillary thyroid carcinoma and review of the literature. Acta Otolaryngol 2011;131(12):1341-8.

6) Togashi T, Sugitani I, Toda K, Kawabata K, Takahashi S. Surgical management of retropharyngeal nodes metastases from papillary thyroid carcinoma. World J Surg 2014;38(11):2831-7.

7) Desuter G, Lonneux M, Plouin-Gaudon I, Jamar F, Coche E, Weynand B, et al. Parapharyngeal metastases from thyroid cancer. Eur J Surg Oncol 2004;30(1):80-4.

8) Rouvière H, Tobias MJ. Anatomy of the human lymphatic system. Ann Arbor, Michigan: Edwards Brothers;1938. p.5-65.

9) Lombardi D, Nicolai P, Antonelli AR, Maroldi R, Farina D, Shaha AR. Parapharyngeal lymph node metastasis: An unusual presentation of papillary thyroid carcinoma. Head Neck 2004;26(2):190-6. 